\title{
Nanopigmented Acrylic Resin Cured Indistinctively by Water Bath or Microwave Energy for Dentures
}

\author{
L. S. Acosta-Torres, ${ }^{1}$ M. C. Arenas, ${ }^{1}$ R. E. Nuñez-Anita, ${ }^{2}$ F. H. Barceló-Santana, ${ }^{3}$ \\ C. A. Álvarez-Gayosso, ${ }^{3}$ J. Palacios-Alquisira, ${ }^{4}$ J. de la Fuente-Hernández, ${ }^{1}$ \\ Marcos Cajero-Juárez, ${ }^{2}$ and V. M. Castaño ${ }^{5,6}$ \\ ${ }^{1}$ Escuela Nacional de Estudios Superiores, Unidad León, Licenciatura en Odontología, \\ Universidad Nacional Autónoma de México, Boulevard UNAM No. 2011 Predio el Saucillo y el Potrero, 36969 León, GTO, Mexico \\ ${ }^{2}$ Facultad de Medicina Veterinaria y Zootecnia, UMSNH, Km. 9.5 Carretera Morelia-Zinapécuaro, Col. La Palma, \\ 58893 Tarímbaro, MICH, Mexico \\ ${ }^{3}$ Laboratorio de Materiales Dentales, División de Estudios de Posgrado e Investigación, Facultad de Odontología, \\ Universidad Nacional Autónoma de México, Avenida Universidad No. 3000, Colonia Copilco, 04510 México, DF, Mexico \\ ${ }^{4}$ Posgrado de la Facultad de Química, Universidad Nacional Autónoma de México, Avenida Universidad No. 3000, \\ Colonia Copilco, 04510 México, DF, Mexico \\ ${ }^{5}$ Departamento de Ingeniería Molecular de Materiales, Centro de Física Aplicada y Tecnología Avanzada, \\ Universidad Nacional Autónoma de México, Campus Juriquilla, Boulevard Juriquilla No. 3001, 76230 Juriquilla, QRO, Mexico \\ ${ }^{6}$ Centro de Tecnología Avanzada, (CIATEQ), av. El Retablo 150, 76150 Querétaro, Qro, Mexico
}

Correspondence should be addressed to M. C. Arenas; carenas@enes.unam.mx

Received 9 July 2013; Revised 25 December 2013; Accepted 27 December 2013; Published 20 February 2014

Academic Editor: Il-Kwon Oh

Copyright ( 2014 L. S. Acosta-Torres et al. This is an open access article distributed under the Creative Commons Attribution License, which permits unrestricted use, distribution, and reproduction in any medium, provided the original work is properly cited.

The highlight of this study was the synthesis of nanopigmented poly(methyl methacrylate) nanoparticles that were further processed using a water bath and/or microwave energy for dentures. The experimental acrylic resins were physicochemically characterized, and the adherence of Candida albicans and biocompatibility were assessed. A nanopigmented acrylic resin cured by a water bath or by microwave energy was obtained. The acrylic specimens possess similar properties to commercial acrylic resins, but the transverse strength and porosity were slightly improved. The acrylic resins cured with microwave energy exhibited reduced C. albicans adherence. These results demonstrate an improved noncytotoxic material for the manufacturing of denture bases in dentistry.

\section{Introduction}

Poly(methyl methacrylate) (PMMA) is the main commercial acrylic resin used in denture fabrication [1]. Advances in polymer science for denture bases have developed different molding and activation techniques [2]. The heat- and microwave-generated commercial acrylic resins have similar chemical formulations [3], but there are specific components to the curing of resins for each technique. The microwave method for PMMA denture base polymerization has the following advantages: shorter times for curing and for attaining the plastic phase and less porosity and excellent adaptation of a prosthetic material in contrast to conventional heat-water polymerization. Despite these advantages, this method has limited use in the dentistry field [4].

A few studies regarding the experimental acrylic resin have been reported. In our previous works, spherical particles of an experimental acrylic resin were synthesized by the polymerization suspension technique using sodium alginate or gelatin as suspension agents. A clear PMMA was obtained and the morphology, particle size, thermal behavior, and flexural properties were fully characterized. The result was a 
material comparable with the commercial acrylic resins for dentures when the material was processed by a water bath or a microwave technique [5]. Metallic oxide nanoparticles were included in the synthesis as pigments to obtain a pink PMMA that was similar to the gums in color. These nanopigmented PMMA particles were thermopolymerized with the water bath technique, and they presented lower porosity and solubility compared with the clear PMMA [6]. Different types of fibers [7] or silver nanoparticles [8] were added in the nanopigmented PMMA formulation, but the fibers did not change the flexural strength, and the nanoparticles decreased this value, despite an improvement of the antifungal effect against Candida albicans.

The nanopigmented PMMA needs to be assessed in all the physical, antimicrobial, and cytocompatible properties when it is processed indistinctively by a water bath and microwave thermopolymerization techniques. These methods do not sacrifice the resin's physicochemical properties and might generate a cheap and nontoxic material. The material needs to be compared with the commercial acrylic resins available for each specific technique. The material was compared with the Lucitone 199 and Acron MC acrylic resins for denture bases that are commercially available for specific water bath and microwave polymerization techniques, respectively.

\section{Materials and Methods}

Methyl methacrylate (MMA) monomer and benzoyl peroxide (both from Sigma-Aldrich, St. Louis, MO, USA) were used as received. Sodium alginate (Manufacturera-DentalContinental, Mexico) was used as a suspension agent. Iron oxide and titanium oxide nanoparticles $\left(\mathrm{Fe}_{2} \mathrm{O}_{3}\right.$ [R-4511] and $\mathrm{TiO}_{2}$ [RF-9400] (González-Cano y Compañía, Mexico) were used as pigments. The commercial heat-cured acrylic resins Lucitone 199 (water bath thermopolymerized; Dentsply/Trubyte, York, PA) and Acron MC (GC Lab Technologies, Alsip, IL) were selected for the comparisons.

\section{Synthesis of Nanopigmented PMMA Particles}

Nanopigmented PMMA, a pink substance similar to the gums, was synthesized by the suspension polymerization technique described in previous work [5]. The brief method was as follows. In a five-neck flask, $200 \mathrm{~mL}$ of deionized water, $1.5 \mathrm{~g}$ of sodium alginate, $200 \mathrm{~g}$ of MMA monomer, and $0.2 \mathrm{~g}$ of initiator were mixed with reflux; nitrogen gas was added; the mixture was stirred $(1,200 \mathrm{rpm})$ and heated at $70^{\circ} \mathrm{C}$ for $2 \mathrm{~h}$. The $\mathrm{TiO}_{2}$ and $\mathrm{Fe}_{2} \mathrm{O}_{3}$ nanopigments were dissolved in $30 \mathrm{~mL}$ of deionized water and added to the reactor $30 \mathrm{~min}$ before the initiator incorporation. Constant stirring throughout the reaction was used to ensure equal distribution of pigments. When the reaction was finished and the PMMA particles had sedimented, they were separated by decantation. The PMMA was washed with deionized water four times until the water was clear to eliminate the nonreactant products. The polymer particles were dried at room temperature.

\section{Characterization of Nanopigmented PMMA Particles}

The nanopigmented PMMA, Lucitone 199, and Acron MC powders were characterized. Fourier transform infrared (FTIR) spectroscopy was conducted in a Bruker Vector 33 Instrument using the transmittance technique. The samples were prepared in $\mathrm{KBr}$ translucent disks and analyzed with 17 scans in the wavelength region between 400 and $4,000 \mathrm{~cm}^{-1}$.

For scanning electron microscopy (SEM) analysis, the polymer particles were coated with gold by vacuum evaporation, and the observations were carried out with a JSM6060LV scanning microscope (JEOL, Peabody, MA). The particle size distribution and standard deviation were obtained for each acrylic resin.

\section{Water Bath and Microwave Polymerization for Specimen Preparation}

To obtain the PMMA specimens, the nanopigmented PMMA powder was separated in two parts to form two experimental groups. Mixtures were prepared with the powders of each group and were collocated in three molds with the following dimensions: $65 \times 10 \times 2.5 \mathrm{~mm}, 50 \times 0.5 \mathrm{~mm}$, and $10 \times 2 \mathrm{~mm}$.

The first group, designated PMMA-wb, was obtained by mixing the PMMA with a MMA monomer $(3: 1)$ and benzoyl peroxide (1\%), packing the mixture into metallic molds, and processing in a water bath for $90 \mathrm{~min}$ at $70^{\circ} \mathrm{C}$ and then for $30 \mathrm{~min}$ at $90^{\circ} \mathrm{C}$. The second group, designated PMMA-mw, was obtained by mixing the PMMA particles with a MMA monomer $(3: 1)$ and benzoyl peroxide (1\%) and packing the mixture into polyester molds, which was followed by curing with microwave energy at $500 \mathrm{~W}$ for $3 \mathrm{~min}$. After the curing process, the molds were cooled at room temperature for $30 \mathrm{~min}$ and placed into cold water at $4^{\circ} \mathrm{C}$ for $30 \mathrm{~min}$ before opening the molds.

The commercial acrylic resins Lucitone 199 and Acron $\mathrm{MC}$ were cured following the manufacturers' instructions.

The specimens obtained were plates of $65 \times 10 \times 2.5 \mathrm{~mm}$ for the flexural strength and flexural modulus calculations $(n=10)$, discs of $50 \times 0.5 \mathrm{~mm}$ for the water sorption and solubility tests $(n=10)$, and discs of $10 \times 2 \mathrm{~mm}$ for the $C$. albicans adherence and cytotoxicity assays $(n=9)$. All the specimens were trimmed with wet abrasive paper of grit 100 and 300 (Fandeli, Mexico) prior to use.

Table 1 summarizes the curing technique, batch number, and viscosity molecular weight of each evaluated acrylic resin. The mentioned molecular weight belongs to the experimental PMMA without the nanopigment particles.

\section{Characterization of the Cured Nanopigmented PMMA Specimens}

The processed PMMA-wb, PMMA-mw, Lucitone 199, and Acron MC samples were tested as follows.

Thermogravimetrical analysis (TGA) was carried out on a fragment of each group of the nanopigmented PMMA cured resins using a thermogravimetric analyzer (TA Instrument 
TABLE 1: Summary of processing methods for curing of commercial acrylic resin and experimental PMMA.

\begin{tabular}{|c|c|c|c|}
\hline Acrylic resin & Processing method & Manufacturer (location) & Viscosity mol wt $(\mathrm{g} / \mathrm{mol})^{\mathrm{a}}$ \\
\hline Lucitone 199 & $\begin{array}{l}\text { Water bath cured at } \\
70^{\circ} \mathrm{C} \text { for } 90 \mathrm{~min} \text { and } 90^{\circ} \mathrm{C} \text { for } 30 \mathrm{~min}\end{array}$ & $\begin{array}{c}\text { Dentsply/Trubyte (York, } \\
\text { PA) }\end{array}$ & $19 \times 10^{-5}$ \\
\hline Acron MC & $\begin{array}{c}\text { Microwave cured at } \\
500 \mathrm{~W} \text { for } 3 \mathrm{~min}\end{array}$ & GC (Alsip, IL) & $14 \times 10^{-5}$ \\
\hline $\begin{array}{l}\text { Experimental } \\
\text { PMMA }\end{array}$ & $\begin{array}{l}\text { Water bath cured } \\
\text { at } 70^{\circ} \mathrm{C} \text { for } 90 \mathrm{~min} \text { and } 90^{\circ} \mathrm{C} \text { for } 30 \mathrm{~min} \text {; } \\
\text { microwave cured at } 500 \mathrm{~W} \text { for } 3 \mathrm{~min}\end{array}$ & - & $36 \times 10^{-5}$ \\
\hline
\end{tabular}

${ }^{\mathrm{a}}$ The viscosity molecular weight was reported previously [5].

Q500 V6.3) at a heating rate of $10^{\circ} \mathrm{C} / \mathrm{min}$ up to $900^{\circ} \mathrm{C}$ in an $\mathrm{N}_{2}$ atmosphere.

For the characterization of the flexural behavior, the samples were placed in a transverse deflection machine (Mecmesin, Sterling, VA) at $5 \mathrm{~N} / \mathrm{min}$ until they fractured. The flexural modulus and transverse strength values were obtained using the equations reported previously $[5,6]$.

For the water sorption and solubility test, 10 discs $(n=$ 10) were weighed (reported in $\mathrm{mg}$ ), placed in a silica gel desiccator, and weighed every $24 \mathrm{~h}$ until a constant mass $\left(m_{1}\right)$ was obtained. The discs were placed in distilled water for 7 days at $37 \pm 1^{\circ} \mathrm{C}$. The discs were then dried and weighed $\left(m_{2}\right)$. The discs were placed in the desiccator again and weighed every $24 \mathrm{~h}$ until a constant mass $\left(m_{3}\right)$ was reached. The area $(A)$ of each sample was calculated (reported in $\mathrm{cm}^{2}$ ). The water sorption (Ws) and solubility (Sl) were calculated according to ADA 12, 1990 [9], as follows: $\mathrm{Ws}=\left(m_{2}-m_{1}\right) / A$; $\mathrm{Sl}=\left(m_{1}-m_{3}\right) / A$.

For the porosity test, the fractured plates were adjusted to obtain plates of $30 \times 10 \times 2.5 \mathrm{~mm}$. They were weighed to obtain their mass, and the volume of each sample was calculated $\left(V_{\mathrm{sp}}\right)$. The samples were weighed every $24 \mathrm{~h}$ and placed in a silica gel desiccator until a constant mass was obtained. The volume of each sample was determined, and the internal porosity $\left(V_{\text {ip }}\right)$ was calculated as follows:

$$
V_{\text {ip }}=V_{\mathrm{sp}}-\frac{W a}{\left(d_{r}-d_{a}\right)} \text {. }
$$

$W a$ is the weight of the sample (in $\mathrm{g}$ ), $d_{r}$ is the acrylic resin density $\left(1.198 \mathrm{~g} / \mathrm{cm}^{3}\right), d_{a}\left(0.00123 \mathrm{~g} / \mathrm{cm}^{3}\right)$ is the Mexico City air density (at $T=294 \mathrm{~K}, 78 \mathrm{kPa}$ ), and $V_{\text {sp }}$ is the volume of the sample (in $\mathrm{cm}^{3}$ ).

One of the broken parts from each group after the flexural tests was used to observe the fracture zone by SEM.

The contact angles of the PMMA polymer films have been measured by the spheroidal segment method using a contact angle measurement system [10].

For the biological testing ( $C$. albicans adherence and cytotoxicity assays), C. albicans strain 90026 (American Type Culture Collection, Manassas, VA) was cultured in 24 -well plates at a density of $1 \times 10^{5}$ cells $/ \mathrm{mL}$. The PMMA samples were sterilized by exposing both faces to ultraviolet irradiation for $5 \mathrm{~min}[8,11]$. Each acrylic resin sample was placed in contact with the microorganisms for $24 \mathrm{~h}$, and the samples were removed and washed with distilled water under stirring conditions. The samples were placed in new 24 -well plates, and $100 \mu \mathrm{L}$ of benzalkonium chloride was added to each sample to extract the adhered $C$. albicans cells. The plate contents were stirred for $15 \mathrm{~min}$, and the samples were removed. A microbial cell viability assay based on luminescent ATP measurements (BacTiter Glo; Promega, Fitchburg, WI) was performed to determine the number of viable cells that had adhered to the composite resins. Briefly, extract aliquots $(20 \mu \mathrm{L}$ each) were mixed with $30 \mu \mathrm{L}$ of BacTiter Glo reagent in 1.5-mL clear Eppendorf tubes, and the luminescence was recorded after 5 min using a luminometer (Turner Biosystems, Sunnyvale, CA) at an emission wavelength of $590 \mathrm{~nm}$. The relative luminescence intensity, in $10 \mathrm{sec}$ integration periods, was measured in triplicate.

A MTT assay was performed using NIH 3T3 mouse fibroblast-like cells (ATCC No. CRL-1658). The nanopigmented and commercial PMMA samples were sterilized by exposing both faces to ultraviolet irradiation for $5 \mathrm{~min}$. The cells were exposed to acrylic resins specimens, and proliferation was assessed by measuring the reductase enzymatic activity based on the transformation of 3(4,5-dimethylthiazol-2-yl)-2,5-diphenyltetrazolium bromide (MTT) into the colored, reduced form of MTT [12]. After 24 and $48 \mathrm{~h}$ incubation times, the resins were removed, the MTT assay was performed following the manufacturer's instructions (Sigma-Aldrich), and the absorbance was measured in a microplate reader (Bio-Rad 680) at a wavelength of $655 \mathrm{~nm}$.

The viability percentage was calculated as follows: [(optical density of the samples)/(optical density of the control group)] $\times 100$. The control group was cultured without acrylic resins. The samples were analyzed in triplicate, and three independent experiments were performed.

For the statistical analysis, One-Way Analysis of Variance $(P<0.05)$ and Tukey tests were applied for the water sorption, solubility, flexural modulus, transverse strength, porosity, cytotoxicity, and C. albicans adherence values.

\section{Results and Discussion}

7.1. FTIR and Size Distribution of Nanopigmented PMMA. Figure 1 shows the infrared spectrum of the nanopigmented PMMA compared with those of the commercial PMMA resins (Lucitone 199 and Acron MC) in the wavelength range of $4,000 \mathrm{~cm}^{-1}$ to $650 \mathrm{~cm}^{-1}$. All the spectra present similar responses, in which the characteristic peaks of the PMMA were observed $[9,10,13]$. The peaks at $2,950 \mathrm{~cm}^{-1}$ and 


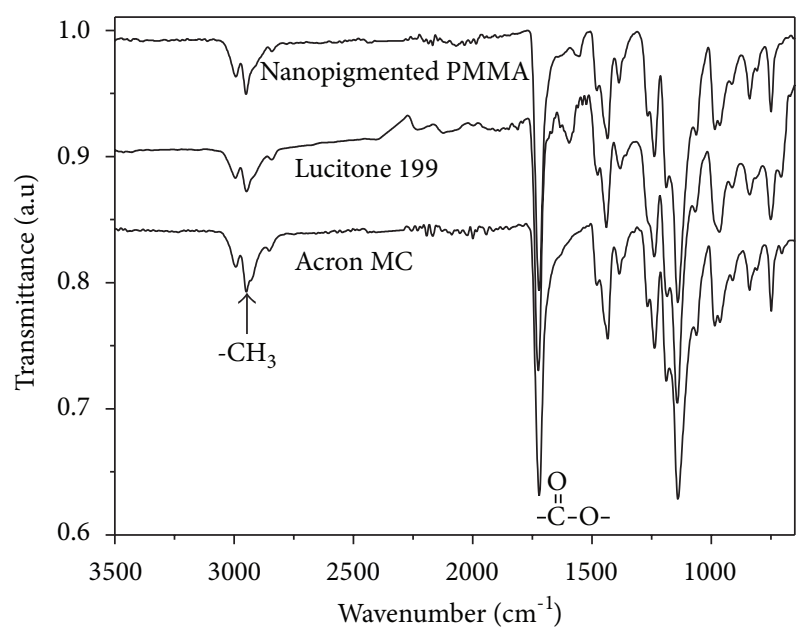

FIGURE 1: Infrared spectra of polymer particles of nanopigmented PMMA, Lucitone 199, and Acron MC showing the main stretching bands of the PMMA molecule.

$1,720 \mathrm{~cm}^{-1}$ correspond to the $\mathrm{C}-\mathrm{H}$ and $\mathrm{C}=\mathrm{O}$ (ester carbonyl) stretching vibrations, and the band at $1,434 \mathrm{~cm}^{-1}$ is due to the $\mathrm{C}-\mathrm{H}$ bending vibrations. Other peaks at low frequencies, $1,139 \mathrm{~cm}^{-1}, 840 \mathrm{~cm}^{-1}$, and $752 \mathrm{~cm}^{-1}$, are related to the $\mathrm{H}-\mathrm{C}-$ $\mathrm{H}$ stretching vibration, to the $\mathrm{O}-\mathrm{C}-\mathrm{O}$ deformation vibration, and to the puckering vibration of PMMA, respectively. The absence of peaks in the range of $1,680 \mathrm{~cm}^{-1}$ to $1,640 \mathrm{~cm}^{-1}$ indicates that the MMA monomer was fully polymerized [12].

Despite the similarities in the infrared results for the PMMA samples, the particle sizes were very different according to the SEM results (not shown here). The nanopigmented PMMA particle sizes were between 4.5 and $10 \mu \mathrm{m}$, and the sizes for Lucitone 199 and Acron MC were in the range of 30 to $60 \mu \mathrm{m}$ and 60 to $120 \mu \mathrm{m}$, respectively. Figure 2 shows the distribution of the particles sizes, where the averages for the samples were $16.51 \mu \mathrm{m} \pm 6.5 \mu \mathrm{m}$ (nanopigmented PMMA), $32.23 \mu \mathrm{m} \pm 10.8 \mu \mathrm{m}$ (Lucitone 199), and $69.69 \mu \mathrm{m} \pm 23.88 \mu \mathrm{m}$ (Acron MC).

\subsection{Evaluation of Nanopigmented PMMA Cured Using a Water} Bath and Microwave Thermopolymerization. The nanopigmented PMMA particles were cured by a water bath and by microwave methods. The thermal stability of the PMMA specimens (PMMA-wb and PMMA-mw, Lucitone and Acron $\mathrm{MC}$ ) was determined from the thermogram profiles (Figure 3). As shown in Figure 3(a), abrupt reductions in weight at approximately $300^{\circ} \mathrm{C}$ to $400^{\circ} \mathrm{C}$ (80 to $98 \%$ weight loss) were observed for all specimens, and these were attributed to the complete degradation of the polymer chain. As shown in the inset of Figure 3(a), the profile of PMMA-wb is slightly later than Lucitone 199, indicating a better stability. PMMA-mw is slightly less thermally stable than Acron MC. Based on the derived weight profiles (Figure 3(b)), the two main peaks between $276^{\circ} \mathrm{C}$ and $285^{\circ} \mathrm{C}$ (12 to $20 \%$ weight loss) and between $364^{\circ} \mathrm{C}$ and $379^{\circ} \mathrm{C}$ (80 to $98 \%$ weight loss) could be attributed to other components in the commercial acrylic resins, such as plasticizers, comonomers, or crosslinking agents with different thermal behaviors. The manufacturer specifications of Lucitone 199 mention the presence of ethylene dimethacrylate in its liquid composition, and Acron MC presents a copolymer of poly (methyl methacrylate/ethylacrylate) in the powder formulation. It is clear that microwave energy influences in thermal stability of the nanopigmented PMMA specimens.

In the flexural modulus, there were no statistically significant differences between any of the tested groups $(P>0.05)$. PMMA-wb, Lucitone 199 and Acron MC showed slightly higher transverse strength values than the nanopigmented PMMA processed by microwaves (PMMA-mw) (Table 2), and this value fulfilled the minimum allowed value according to ISO 1567 (65 MPa) [14]. These values are still better compared with those of other commercial acrylic resins [15].

One important property of acrylates is water sorption and release, which allows for dimensional instability, subjecting the material to internal stresses that might result in crack formation and eventually might fracture the denture. The water molecules spread between the macromolecules of the material, forcing them apart and affecting the dimensional behavior and denture stability. Water sorption and solubility of these materials should be as low as possible [16]. In the water sorption test, there was a marked difference. The PMMA-wb had a lower value $\left(0.27 \pm 0.02 \mathrm{mg} / \mathrm{cm}^{2}\right)$, and Lucitone 199 had a higher value $\left(0.37 \pm 0.04 \mathrm{mg} / \mathrm{cm}^{2}\right)$. The materials processed by microwave energy had similar results. All the groups were tested for water sorption and solubility according to the ADA number 12-required values [17], which were lower than 0.8 and $0.04 \mathrm{mg} / \mathrm{cm}^{2}$, respectively.

The mechanical properties of denture base materials decrease as the solubility increases. One study showed that water bath polymerization results in enhanced mechanical properties. It has been established that the water sorption and solubility of polymers depend on the homogeneity of the material; less water absorbed and less solubility are presented in a homogeneous material [16]. PMMA-wb presented lower porosity than Lucitone 199, but there were no significant differences between the PMMA-mw and Acron MC. The low porosity of PMMA-wb was in accordance with the expected values, and it is important to emphasize that the porosities of all the nanopigmented PMMA specimens were lower than other acrylic resins [18].

After the flexural behavior evaluations, the topographies of the fractured zone of each specimen were examined in transverse sections by SEM (Figure 4). The micrographs showed irregular surfaces in the four acrylic resins, and the morphology changed according to the curing method. A slightly nonhomogeneous surface for PMMA-mw was observed, which was in concordance with the low transverse strength value.

The mechanical properties and wear resistance of denture materials have improved substantially, but their antibacterial properties are still of great interest [19]. In the present study, a C. albicans adherence assay was performed. Figure 5(a) shows the results of the adherence assay, in which PMMA-wb and Lucitone 199 resulted in slightly higher values than the 


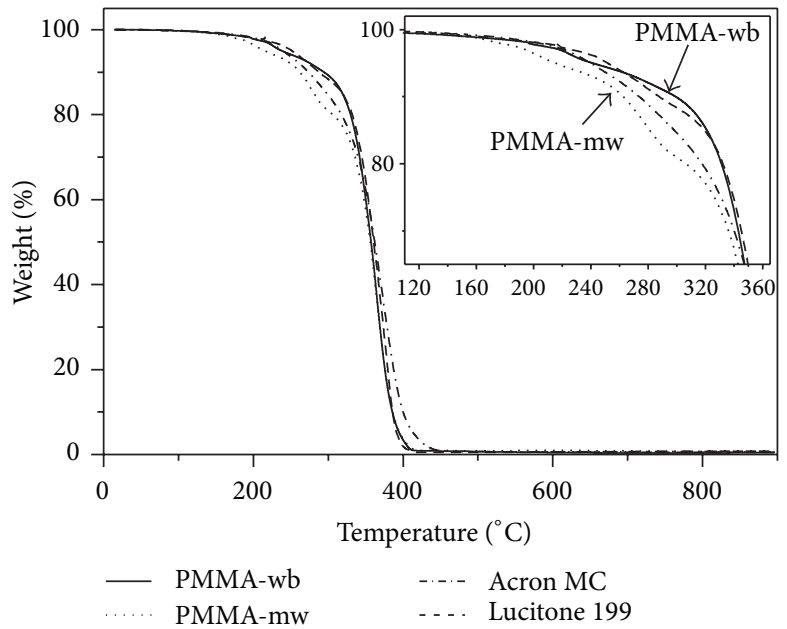

(a)

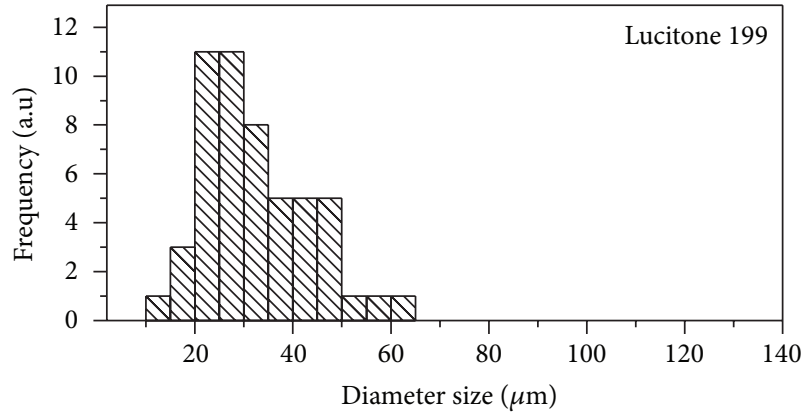

(b)

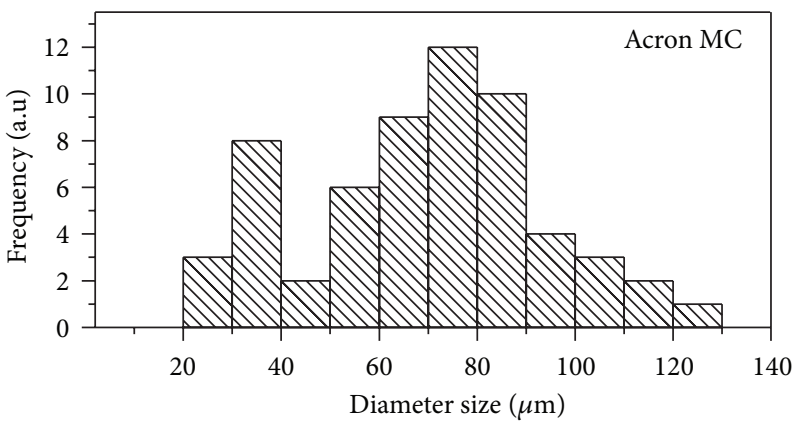

(c)

Figure 2: Statistical particle size distribution of (a) nanopigmented PMMA compared to the commercial acrylic resins: (b) Lucitone 199 and (c) Acron MC.

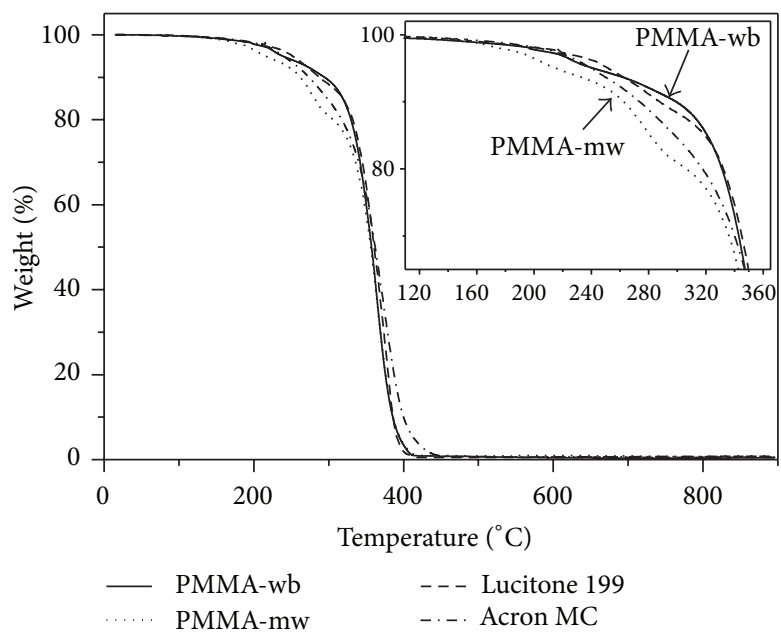

(a)

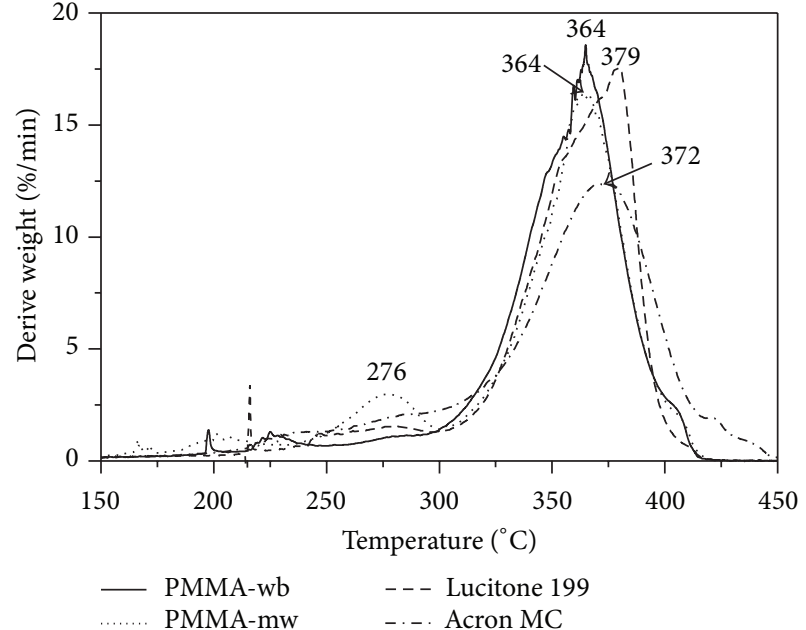

(b)

Figure 3: (a) TGA profiles and (b) derived weight profiles of PMMA-wb and PMMA-mw compared with the commercial acrylic resins. 
TABLE 2: Physical properties of PMMA polymerized by water bath and with microwave energy.

\begin{tabular}{lccccccc}
\hline Acrylic resin & $\begin{array}{c}\text { Flexural } \\
\text { modulus }(\mathrm{GPa})\end{array}$ & $\begin{array}{c}\text { Transverse } \\
\text { strength }(\mathrm{MPa})\end{array}$ & $\begin{array}{c}\text { Water sorption } \\
\left(\mathrm{mg} / \mathrm{cm}^{2}\right)\end{array}$ & $\begin{array}{c}\text { Solubility } \\
\left(\mathrm{mg} / \mathrm{cm}^{2}\right)\end{array}$ & $\begin{array}{c}\text { Porosity } \\
(\%)\end{array}$ & $\begin{array}{c}\text { Contact angle } \\
\left({ }^{\circ}\right)\end{array}$ & $\begin{array}{c}\text { Candida albicans } \\
\text { adherence } \\
\left(\times 10^{5} \mathrm{LRUs}\right)\end{array}$ \\
\hline PMMA-WB & $2.5 \pm 0.14^{*}$ & $77.6 \pm 5.1^{*}$ & $0.27 \pm 0.02^{*}$ & $0.03 \pm 0.004^{*}$ & $4.6 \pm 0.4^{*}$ & $60.29 \pm 1.8$ & $5.8 \pm 1.3$ \\
PMMA-MW & $2.5 \pm 0.30$ & $68.1 \pm 2.8$ & $0.31 \pm 0.06$ & $0.04 \pm 0.005$ & $5.5 \pm 0.5$ & $32.66 \pm 7.4$ & $2.6 \pm 0.5$ \\
Lucitone 199 & $2.5 \pm 0.20^{+}$ & $78.2 \pm 0.2^{+}$ & $0.37 \pm 0.04$ & $0.02 \pm 0.010$ & $6.8 \pm 1.0^{+}$ & $36.02 \pm 4.4$ & $6.3 \pm 2.2$ \\
Acron MC & $2.5 \pm 0.17$ & $75.8 \pm 5.1$ & $0.30 \pm 0.10$ & $0.04 \pm 0.008$ & $5.4 \pm 0.4$ & $53.02 \pm 3.1$ & $1.6 \pm 0.4$ \\
\hline
\end{tabular}

${ }^{*}[6] ;{ }^{+}[7]$.

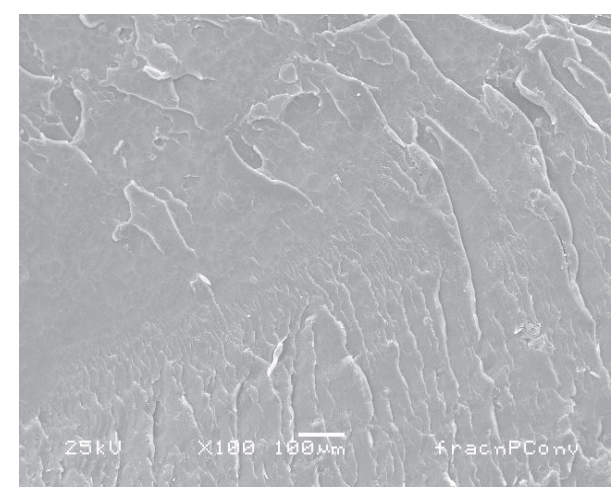

(a)

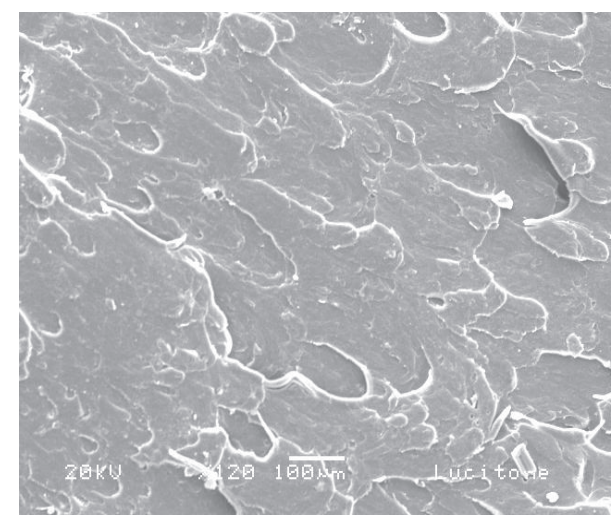

(c)

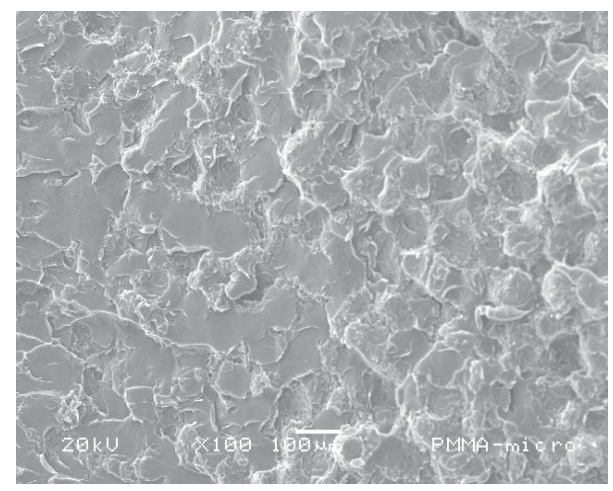

(b)

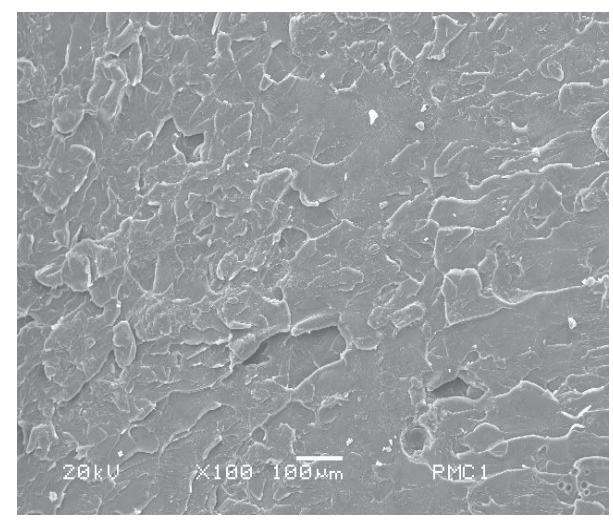

(d)

FIGURE 4: SEM images of the fracture zone of (a) PMMA-wb and (b) PMMA-mw compared with the commercial resins (c) Lucitone 199 and (d) Acron MC.

acrylic resins processed by microwave energy (PMMA-mw, Acron MC). Acron MC showed the lowest value, followed by nanopigmented PMMA-mw, which was indicative of a lower C. albicans adherence compared with PMMA-wb and Lucitone 199. C. albicans possesses various virulence factors, including the capacity to form biofilms, which render antifungal drugs less efficient. C. albicans has the ability to form hyphae, which facilitates soft tissue invasion, allowing the microorganisms to hide from the host defense system [20]. It is difficult to avoid the adhesion of pathogenic microorganisms to the surface of dental materials, though some efforts toward this have been made [21]. The exact mechanisms by which $C$. albicans adheres to acrylic surfaces are unknown, but many factors that affect $C$. albicans adherence have been described, including surface roughness, salivary pellicle formation, hydrophobic property, and electrostatic interactions [22].

The water contact angle was measured to estimate the hydrophobicity of the nanopigmented PMMA and commercial acrylic resins (Table 2). The nanopigmented PMMAwb specimens presented a high water contact angle and a large amount of $C$. albicans. This is contrary to the references, where the adherence was linearly related to high hydrophobicity [22]. These specimens are composed of small particles and have low porosity, which could influence the $C$. albicans adherence. The Acron MC specimens formed with large particles present low amounts of $C$. albicans and high hydrophobicity. The PMMA-mw and Acron MC specimens 


\begin{tabular}{|l|c|}
\hline Acrylic resin & Candida albicans adherence $\left(\times 10^{5}\right.$ LRUs $)$ \\
\hline PMMA-wb & $5.8 \pm 1.3$ \\
\hline PMMA-mw & $2.6 \pm 0.5$ \\
\hline Lucitone 199 & $6.3 \pm 2.2$ \\
\hline Acron MC & $1.6 \pm 0.4$ \\
\hline
\end{tabular}

(a)

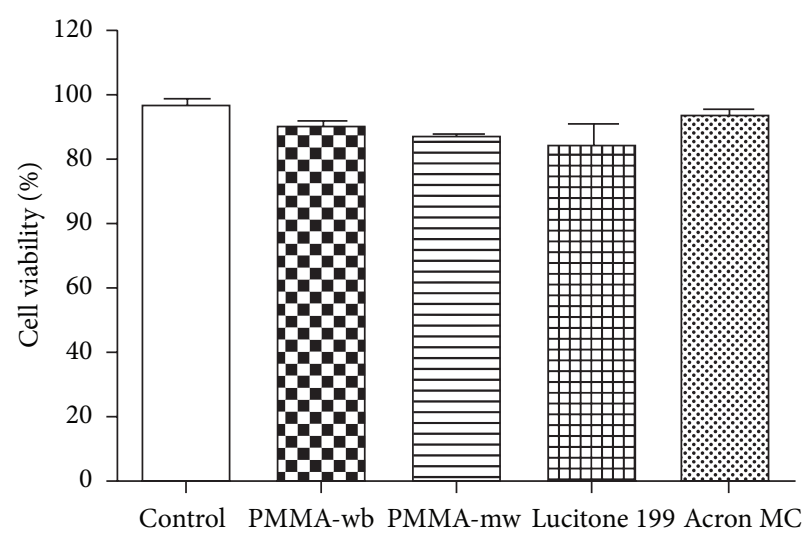

(b)

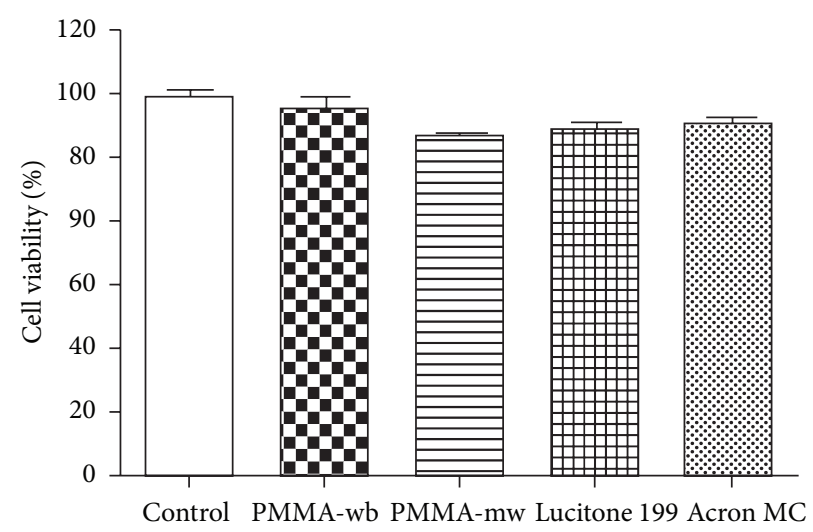

(c)

Figure 5: The antifungal effects and biocompatibility of PMMA-wb and PMMA-mw. (a) The adherence of C. albicans as measured in a luminescent microbial cell viability assay. The luminescence was determined based on light relative units (LRUs). (b) and (c) The viability of NIH 3 T3 cells after exposure to materials for 24 and $48 \mathrm{~h}$, respectively.

cured with microwave energy presented similar porosities and a low amount of C. albicans, and there was a great difference in the particle sizes.

Cytotoxicity tests were designed to determine how the sample material affected a particular cell type. Figures 5(b) and 5(c) show the results of the cytotoxicity assays for all the groups when they were in contact with mouse fibroblast-like NIH 3T3 cell cultures for 24 and $48 \mathrm{~h}$. The MTT test was used because it is based on an evaluation of mitochondrial function after exposure to potential toxic substances [23]. The results were not statistically significantly different $(P>0.05)$, indicating that the synthesized PMMA and the commercial acrylic resins are nontoxic materials.

Consideration must be given to the relative biocompatibility of all denture base materials. Considerations of the incidence and severity of side effects of denture bases have been included as parts of some general studies on dental materials. Local reactions that have been reported are not severe, and the most common are lichenoid reactions in the oral mucosa and skin reactions such as rashes, dermatitis, and eczematous lesions. These reactions depend on the chemical composition of the materials used and their degradation products, absorption, accumulation, and other factors associated with leachable substances from the restoration. Another group of side effects are related to cell proliferation. One study showed that a PMMA-based denture base polymer triggered death signals in cell culture [24]. Another study showed that treatment in a water bath postpolymerization reduced the cytotoxicity of Lucitone 550 [25]. In this work, Lucitone 199 and Acron MC were used as controls, representing noncytotoxic resins. The results showed that no significant differences were observed regarding fibroblast cell viability, therefore PMMA-wb and PMMA-mw can be considered biocompatible materials.

\section{Conclusions}

Nanopigmented PMMA particles were successfully synthesized and cured by a water bath or by microwaves for denture bases. According to results, the particle sizes and the curing process influence the physical properties of the PMMA. The PMMA specimens exhibited good physical and mechanical properties and were noncytotoxic, similar to commercial acrylic resins. These nanopigmented particles will be applied in vivo in the denture field in further work. 


\section{Conflict of Interests}

The authors confirm that they have no conflict of interests regarding the present paper.

\section{Acknowledgments}

The authors wish to thank the following individuals for their excellent technical support: Dra. Genoveva Hernández, Dra. Marina Vega, Mtra. Ma. Lourdes Palma Tirado, Q. Carmen Vázquez, Dr. Antonio Gómez Cortés, Miguel A. Arellano Rodríguez, C. D. Rodrigo Hernández-Medina, Daniel Mondragón, Antonio Prado, and L. E. I. Daniel González Espejel.

\section{References}

[1] M. G. Tu, W.-M. Liang, T.-C. Wu, and S.-Y. Chen, "Improving the mechanical properties of fiber-reinforced acrylic denturebase resin," Materials and Design, vol. 30, no. 7, pp. 2468-2472, 2009.

[2] C. Machado, E. Sanchez, S. S. Azer, and J. M. Uribe, "Comparative study of the transverse strength of three denture base materials," Journal of Dentistry, vol. 35, no. 12, pp. 930-933, 2007.

[3] J. S. Moura, W. J. da Silva, T. Pereira, A. A. del Bel Cury, and R. C. M. Rodrigues Garcia, "Influence of acrylic resin polymerization methods and saliva on the adherence of four Candida species," Journal of Prosthetic Dentistry, vol. 96, no. 3, pp. 205-211, 2006.

[4] M. J. Azzarri, M. S. Cortizo, and J. L. Alessandrini, "Effect of the curing conditions on the properties of an acrylic denture base resin microwave-polymerised," Journal of Dentistry, vol. 31, no. 7, pp. 463-468, 2003.

[5] L. S. Acosta-Torres, F. H. Barceló-Santana, C. A. ÁlvarezGayosso, and J. Reyes-Gasga, "Synthesis and characterization of poly(methyl methacrylate) polymerized by microwave energy or conventional water bath," Journal of Applied Polymer Science, vol. 109, no. 6, pp. 3953-3960, 2008.

[6] L. S. Acosta-Torres, L. M. López Marín, R. E. Nuñez-Anita, G. Hernández-Padrón, and V. M. Castaño, "Biocompatible metal-oxide nanoparticles: nanotechnology improvement of conventional prosthetic acrylic resin," Journal of Nanomaterials, vol. 2011, Article ID 941561, 8 pages, 2011.

[7] V. Moreno-Maldonado, L. S. Acosta-Torres, F. H. BarcelóSantana, R. D. Vanegas-Lancón, M. E. Plata-Rodríguez, and V. M. Castaño, "Fiber-reinforced nanopigmented poly(methyl methacrylate) as improved denture base," Journal of Applied Polymer Science, vol. 126, pp. 289-295, 2012.

[8] L. S. Acosta-Torres, I. Mendieta, R. E. Nuñez-Anita, M. CajeroJuárez, and V. M. Castaño-Meneses, "Cytocompatible antifungal acrylic resin containing silver nanoparticles for dentures," International Journal of Nanomedicine, vol. 7, pp. 4777-4786, 2012.

[9] R. W. Walker, L. M. Markillie, A. H. Colotelo et al., "Ultraviolet radiation as disinfection for fish surgical tools," Animal Biotelemetry, vol. 1, article 4, pp. 1-11, 2013.

[10] S. Wei, J. Sampathi, Z. Guo et al., "Nanoporous poly(methyl methacrylate)-quantum dots nanocomposite fibers toward biomedical applications," Polymer, vol. 52, no. 25, pp. 5817-5829, 2011.
[11] V. Di Noto, K. Vezzù, G. A. Giffin, F. Conti, and A. Bertucco, "Effect of high pressure $\mathrm{CO}_{2}$ on the structure of PMMA: a FTIR study," Journal of Physical Chemistry B, vol. 115, no. 46, pp. 13519-13525, 2011.

[12] T. L. Tsai, C. C. Lin, G. L. Guo, and T. C. Chu, "Effects of microwave-assisted digestion on decomposition behavior of polymethyl methacrylate (PMMA)," Materials Chemistry and Physics, vol. 108, no. 2-3, pp. 382-390, 2008.

[13] D. Padalia, U. C. Johri, and M. G. H. Zaidi, "Study of cerium doped magnetite $\left(\mathrm{Fe}_{3} \mathrm{O}_{4}\right.$ :Ce)/PMMA nanocomposites," Physica $B$, vol. 407, no. 5, pp. 838-843, 2012.

[14] "Dentistry-Denture Base Polymers," ISO 1567, International Organization for Standardization, Geneva, Switzerland, 1999.

[15] A. Sodagar, M. Z. Kassaee, A. Akhavan, N. Javadi, S. Arab, and M. J. Kharazifard, "Effect of silver nano particles on flexural strength of acrylic resins," Journal of Prosthodontic Research, vol. 56, pp. 120-124, 2012.

[16] P. Pfeiffer and E.-U. Rosenbauer, "Residual methyl methacrylate monomer, water sorption, and water solubility of hypoallergenic denture base materials," Journal of Prosthetic Dentistry, vol. 92, no. 1, pp. 72-78, 2004.

[17] ADA-12, "Revised American Dental Association Specification No. 12 for denture base polymers," Reports of Councils and Bureaus/ JADA, 1990.

[18] C. P. Lai, M.-H. Tsai, M. Chen, H.-S. Chang, and H.-H. Tay, "Morphology and properties of denture acrylic resins cured by microwave energy and conventional water bath," Dental Materials, vol. 20, no. 2, pp. 133-141, 2004.

[19] M. Z. Kassaee, A. Akhavan, N. Sheikh, and A. Sodagar, "Antibacterial effects of a new dental acrylic resin containing silver nanoparticles," Journal of Applied Polymer Science, vol. 110, no. 3, pp. 1699-1703, 2008.

[20] C. Messier, F. Epifano, S. Genovese, and D. Grenier, "Inhibition of Candida albicans biofilm formation and yeast-hyphal transition by 4-hydroxycordoin," Phytomedicine, vol. 18, no. 5, pp. 380-383, 2011.

[21] L. Zhou, Z. Tong, G. Wu et al., "Parylene coating hinders Candida albicans adhesion to silicone elastomers and denture bases resin," Archives of Oral Biology, vol. 55, no. 6, pp. 401-409, 2010.

[22] C. A. Zamperini, A. L. Machado, C. E. Vergani, A. C. Pavarina, E. T. Giampaolo, and N. C. Da Cruz, "Adherence in vitro of Candida albicans to plasma treated acrylic resin: effect of plasma parameters, surface roughness and salivary pellicle," Archives of Oral Biology, vol. 55, no. 10, pp. 763-770, 2010.

[23] G. Meriç, J. E. Dahl, and I. E. Ruyter, "Cytotoxicity of silica-glass fiber reinforced composites," Dental Materials, vol. 24, no. 9, pp. 1201-1206, 2008.

[24] M. R. Cimpan, R. Matre, L. I. Cressey et al., "The effect of heatand auto-polymerized denture base polymers on clonogenicity, apoptosis, and necrosis in fibroblasts: denture base polymers induce apoptosis and necrosis," Acta Odontologica Scandinavica, vol. 58, no. 5, pp. 217-228, 2000.

[25] J. H. Jorge, E. T. Giampaolo, C. E. Vergani, A. L. Machado, A. C. Pavarina, and I. Z. Carlos, "Biocompatibility of denture base acrylic resins evaluated in culture of L929 cells: effect of polymerisation cycle and post-polymerisation treatments," Gerodontology, vol. 24, no. 1, pp. 52-57, 2007. 

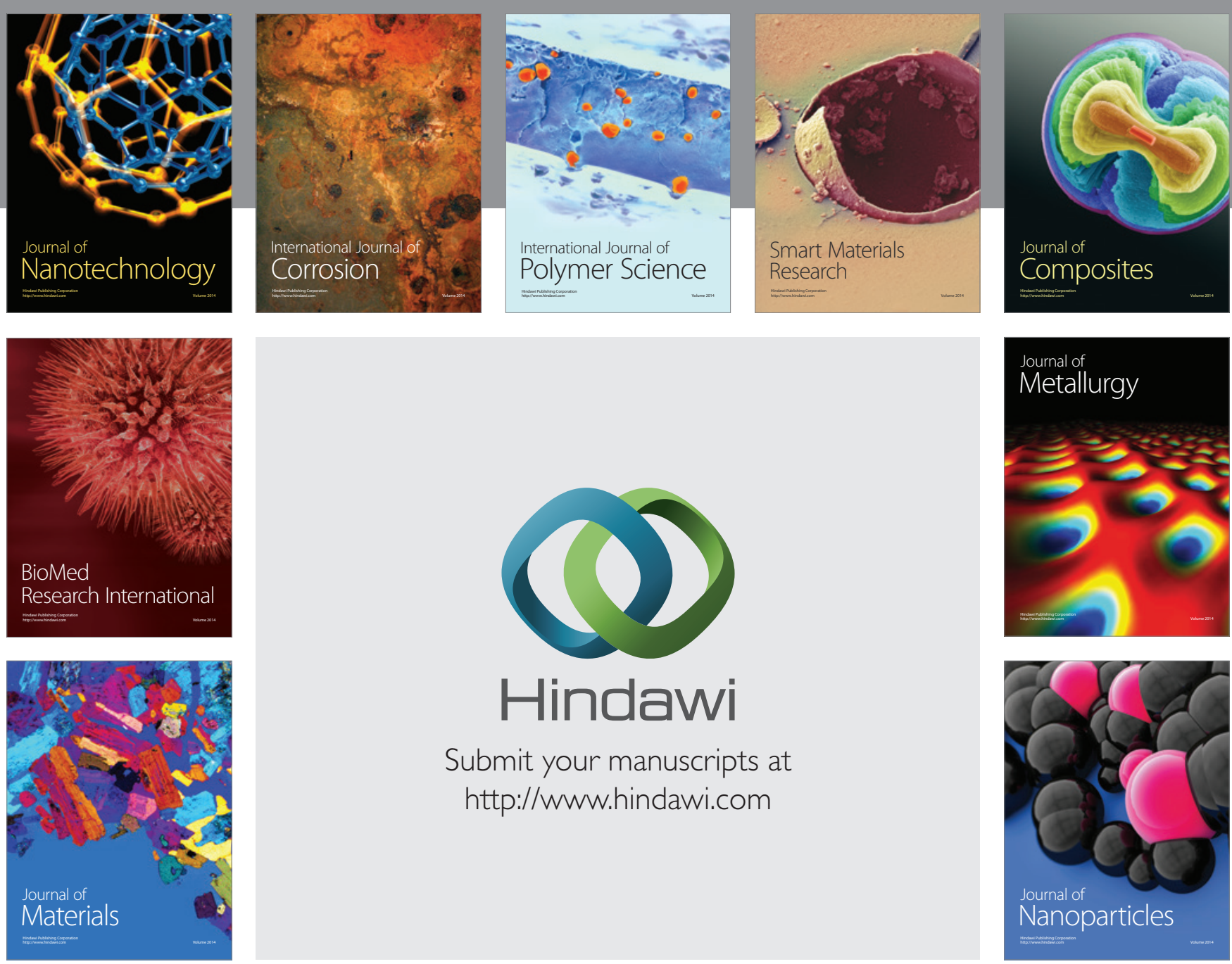

Submit your manuscripts at http://www.hindawi.com
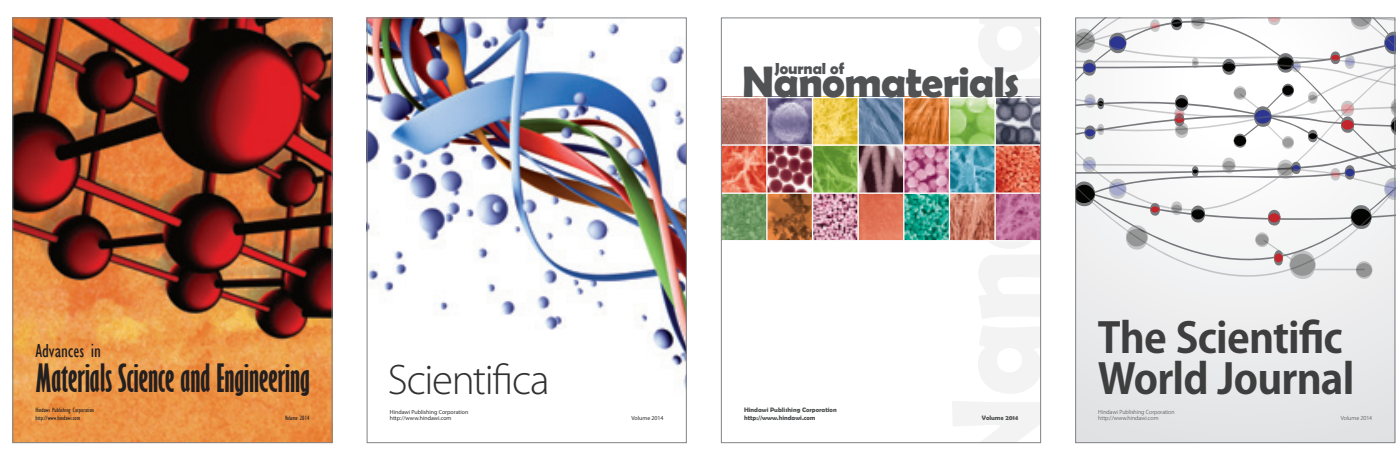

\section{The Scientific World Journal}
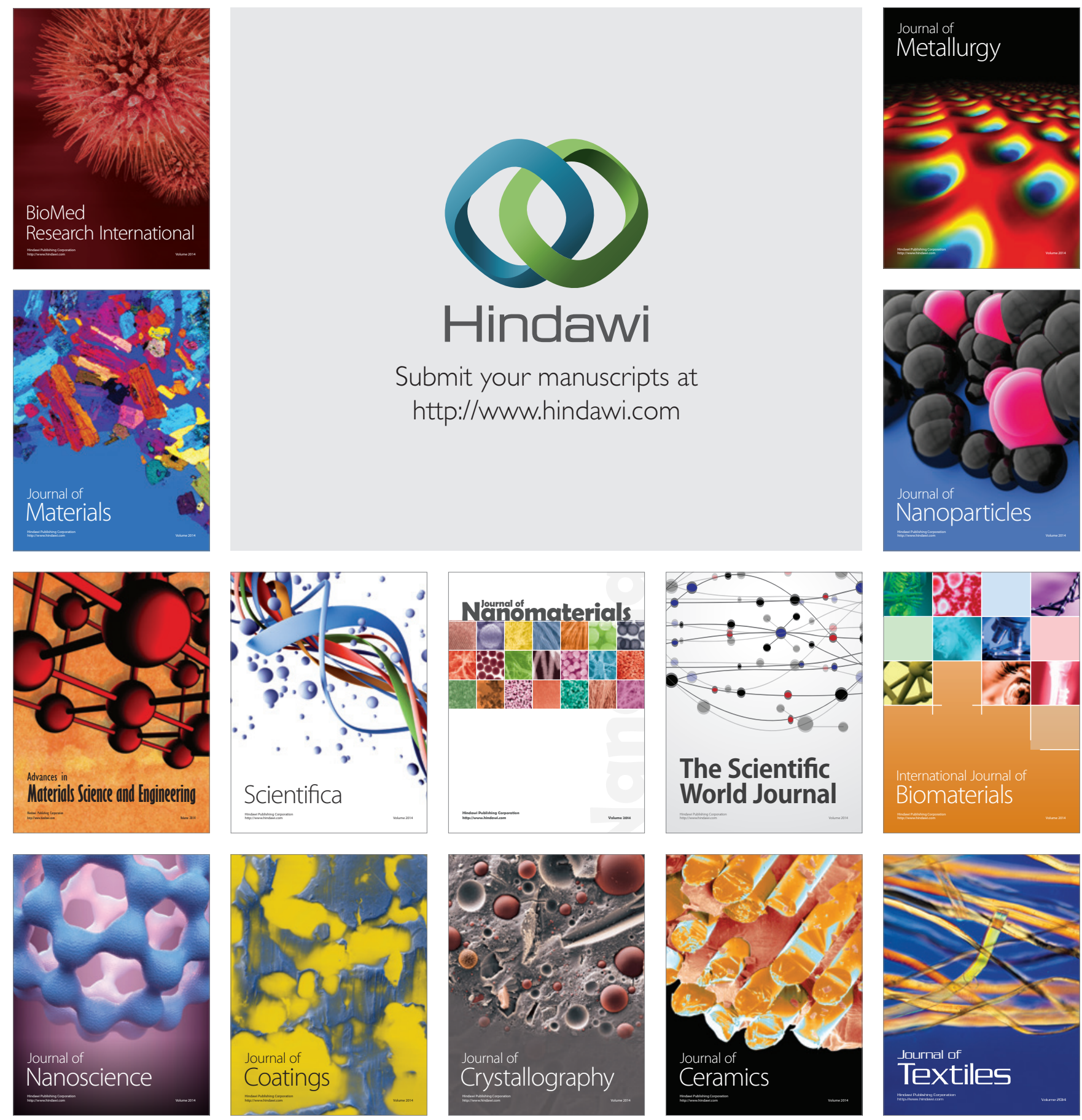